\title{
Factors affecting HCH and DDT in soils around watersheds of Beijing reservoirs, China
}

\author{
Wenyou Hu • Yonglong Lu · Tieyu Wang - Wei Luo • \\ Xiang Zhang · Jing Geng · Guang Wang · Yajuan Shi · \\ Wentao Jiao $\cdot$ Chunli Chen
}

Received: 13 January 2009/Accepted: 13 May 2009/Published online: 31 May 2009

(C) Springer Science+Business Media B.V. 2009

\begin{abstract}
The factors that influence the dynamics of hexachlorocyclohexane $(\mathrm{HCH})$ and dichlorodiphenyltrichloroethane (DDT) in soils around the watersheds of Beijing reservoirs were examined. Compared with other studies on $\mathrm{HCH}$ and DDT in soils and established reference values, the concentrations of $\mathrm{HCH}$ and DDT in soils around our study area were relatively low. The relationships between $\mathrm{HCH}$ and DDT concentrations and land use, soil texture, and soil properties were discussed. $\mathrm{HCH}$ and DDT concentrations were higher in arable soils than those in uncultivated fallow soils. Although land use was the most important factor affecting $\mathrm{HCH}$ and DDT residues, additional factors such as soil texture and soil total organic carbon were also involved in pesticide retention in soils. The results indicated that the historical agricultural applications of $\mathrm{HCH}$ and DDT were the major source of their residues. Atmospheric deposition, as well as long-distance
\end{abstract}

W. Hu · Y. Lu ( $ه) \cdot$ T. Wang · W. Luo ·

X. Zhang · J. Geng · G. Wang · Y. Shi ·

W. Jiao - C. Chen

State Key Laboratory of Urban and Regional Ecology, Research Center for Eco-Environmental Sciences, Chinese Academy of Sciences, 100085 Beijing, China e-mail: yllu@rcees.ac.cn

W. Hu $\cdot$ Y. Lu $\cdot$ X. Zhang $\cdot$ J. Geng $\cdot$ G. Wang $\cdot$ W. Jiao $\cdot$ C. Chen

Graduate School of Chinese Academy of Sciences, 100039 Beijing, China transportation and inputs from surrounding weathered agricultural soils may also serve as important sources of $\mathrm{HCH}$ and DDT residues in the watersheds.

Keywords Hexachlorocyclohexane and dichlorodiphenyltrichloroethane $\cdot$ Soil contamination - Land use · Watershed . Beijing

\section{Introduction}

Hexachlorocyclohexane $(\mathrm{HCH})$ and dichlorodiphenyltrichloroethane (DDT) are persistent hydrophobic contaminants, and are resistant to biotic and abiotic degradation in the environment (Loganathan and Kannan 1994; Kannan et al. 2004; Gonzalez-Lopez et al. 2005). The environmental fate of $\mathrm{HCH}$ and DDT residues is an issue that has received considerable attention over the past three decades due to international regulations on residue levels in food and drinking water (Whylie et al. 2003). Soil is a reservoir for $\mathrm{HCH}$ and DDT and is a source of contamination of food and drinking water. A significant proportion of $\mathrm{HCH}$ and DDT, typically ranging from $20-70 \%$ of a pesticide or its degradation products, may remain in soil following application (Miglioranza et al. 2003b). When $\mathrm{HCH}$ and DDT are applied on a field, several factors control their distribution and fate: some may be lost to the 
atmosphere through volatilization, while others may be carried away by surface runoff or photodegraded by sunlight. Upon entering the soil, $\mathrm{HCH}$ and DDT may bind to soil components (organic matter, mineral particles), be taken up by plants, degraded, and transported to the groundwater or surface waterbodies (Bergstrom and Stenstrom 1998; Miglioranza et al. 2003a). Therefore, the soil ecosystem around watersheds plays an important role in storage, transport, and cycling of HCH and DDT in the soil-plant and soil-water interaction zones. Several earlier studies focused on how $\mathrm{HCH}$ and DDT residues were distributed in the soil (Harner et al. 1999; Feng et al. 2003; Kannan et al. 2003; Gong et al. 2004; Li et al. 2006; Gao et al. 2008), but only a few studies discussed the factors influencing the residue levels and patterns (Oliver et al. 2003; Wang et al. 2005a; Hao et al. 2008; Wang et al. 2008a). Understanding of factors affecting $\mathrm{HCH}$ and DDT residues in soils is important for developing strategies for the monitoring and management of persistent organic pollutants.

As one of the largest agricultural production countries, China has been a major producer and consumer of pesticides, until its ban on production and agricultural use was enforced in 1983 (Wong et al. 2005). In Beijing, water is mainly supplied from Guanting Reservoir (GTR) and Miyun Reservoir (MYR). Around the two reservoirs in Beijing, there are many "green fruit bases". Agriculture in this region is intensive and highly productive, thus agrochemicals were used intensively to improve crop yields in this area in the past (Xue et al. 2005). One report showed that $\mathrm{HCH}$ and DDT accounted for $83.3 \%$ of total pesticides sold in Beijing before 1979 (Wang et al. 2008b). The widespread notion is that the land uses occurring in the watersheds can impact the water quality of streams and rivers draining the watershed (Bergstrom and Stenstrom 1998). HCH and DDT residues have been studied in different soils of this area (Wang et al. 2005b; Zhang et al. 2005; Xue and $\mathrm{Xu}$ 2006), but these reports focused on limited sites in this region and may not reflect the general situation of soil pollution in the Beijing watershed. For understanding of $\mathrm{HCH}$ and DDT levels and to develop an effective soil pollution control plan, detailed and systematic investigation is needed.

The present work is a large-scale and systematic investigation of the residue characteristics and factors affecting $\mathrm{HCH}$ and DDT in soils around the Beijing watershed. The objectives of this study were (1) to determine the residue levels and potential ecological risks of $\mathrm{HCH}$ and DDT in surface soils surrounding the Beijing watershed, (2) to elucidate how the environmental factors affect $\mathrm{HCH}$ and DDT residues in soils, and (3) to identify the sources of $\mathrm{HCH}$ and DDT residues. The information collected will facilitate a better understanding of the residue characteristics and factors affecting $\mathrm{HCH}$ and DDT in soils under various conditions around watersheds.

\section{Materials and methods}

Study area and sample collection

The study area is the watersheds of two Beijing water reservoirs, GTR and MYR (Fig. 1), which supply water to almost 7 million Beijing residents and have been listed as top water-quality protection areas by the government. The GTR is located northwest of Beijing (latitude $40.19^{\circ}-40.50^{\circ}$, longitude $115.43^{\circ}-115.97^{\circ}$ ), with a total area of $130 \mathrm{~km}^{2}$ and a watershed area of $43,402 \mathrm{~km}^{2}$. It is Beijing's second-largest water source for agricultural and industrial purposes, and historically, it was also used for drinking water until 1997. Since then, however, industrial pollution and contamination from farming have substantially degraded the quality of water in this reservoir (Xue et al. 2006; Luo et al. 2007; Wang et al. 2007c). The MYR is located northeast of Beijing (latitude $40.13^{\circ}-$ $40.48^{\circ}$, Longitude $116.40^{\circ}-117.30^{\circ}$ ), with a total area of $188 \mathrm{~km}^{2}$ and a watershed area of $15,788 \mathrm{~km}^{2}$, which makes it the largest water source for Beijing, as well as the largest reservoir in north China. At present, nearly all the drinking-water supply of Beijing comes from this reservoir.

In May 2007, 104 soil samples around GTR and MYR were collected. The locations of the sampling sites are shown in Fig. 1. Throughout the survey, a global positioning system (GPS) was used to locate the sampling sites. The sampling sites covered different types of land-use patterns: orchards, farmlands, and fallow areas. Each sample was made from a mixture of five subsamples collected from the four corners and the center in an area of about $100 \times 100 \mathrm{~m}^{2}$. All soil subsamples were collected at a depth of 0-20 cm using a stainless-steel shovel. Grass and other sundries were removed from the surface of each sample location 
Fig. 1 Study area and soilsampling locations around the watershed of two reservoirs in Beijing

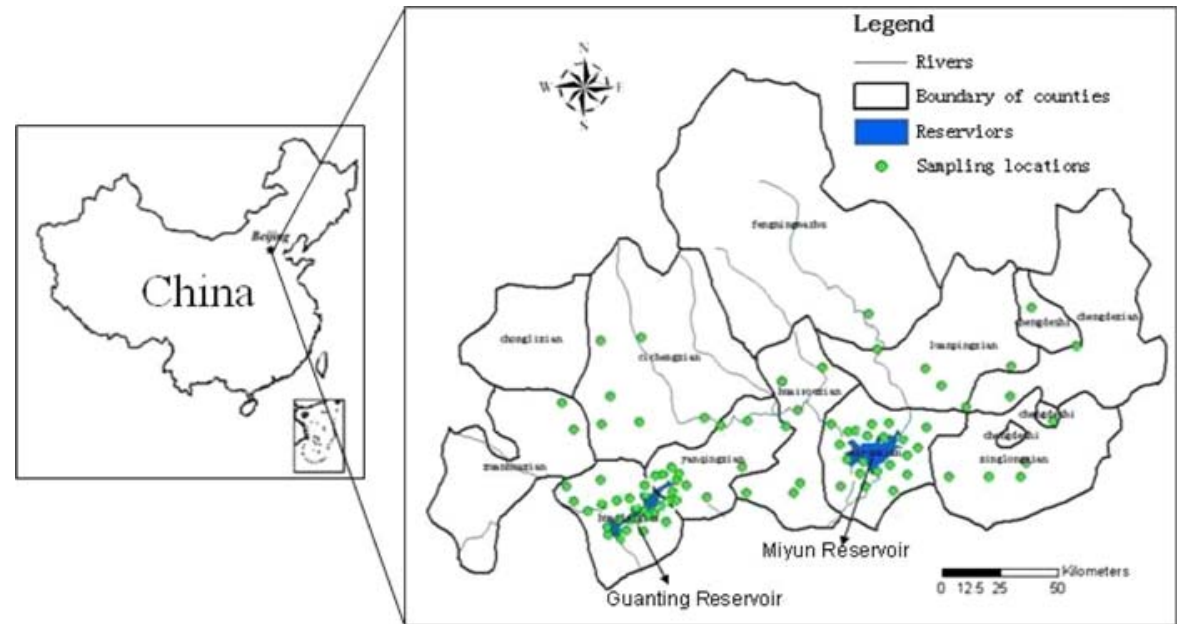

before the sample was collected. The soil samples were air dried at room temperature $\left(22-25^{\circ} \mathrm{C}\right)$ for about 15 days, sieved to $<2 \mathrm{~mm}$, and stored at $4^{\circ} \mathrm{C}$ in pre-cleaned glass jars until analysis.

\section{Reagents}

For extraction of pesticides from the soil, n-hexane and dichloromethane (J.T. Baker, HPLC grade) were used. Anhydrous sodium sulfate (analytical grade) and silica gel (60 mesh, for column chromatograph) were activated at $180^{\circ} \mathrm{C}$ for $24 \mathrm{~h}$. Solid-phase extraction (SPE, $6 \mathrm{ml}$, Supelco, Bellefonte, PA, USA) cartridges containing $1 \mathrm{~g}$ of florisil were washed with $10 \mathrm{ml}$ of $\mathrm{n}$-hexane before use. A mixture of standard solution containing $\alpha-, \beta-, \gamma-, \delta-\mathrm{HCH}$ isomers, $p, p^{\prime}$-DDE, $p, p^{\prime}$-DDD, $o, p^{\prime}$-DDT, and $p, p^{\prime}$ DDT at $1 \mathrm{mg} / \mathrm{g}$ per compound was obtained from the National Research Center for Certified Reference Materials of China. The amount of substances in the extracts was quantified using the internal standard (2, 4, 5, 6-tetrachloro-m-xylene or TCMX) supplied by Supelco (Supelco, Bellefonte, PA, USA).

Sample extraction and cleanup

The analytical method is similar to that described earlier (Wang et al. 2008a). Each soil sample (5.0 g dry weight) was mixed with $1 \mathrm{~g}$ anhydrous sodium sulfate. One milliliter of 2, 4, 5, 6-tetrachloro-mxylene at a concentration of $0.08 \mu \mathrm{g} / \mathrm{ml}$ was added. The mixture was extracted twice with $35 \mathrm{ml}$ of hexane/dichloromethane $(1: 1, \mathrm{v} / \mathrm{v})$ by ultrasonication for $60 \mathrm{~min}$ and then centrifuged. Extracts were concentrated to about $2 \mathrm{ml}$ by rotary evaporation, and further purified with SPE cartridges loaded with $1 \mathrm{~g}$ silica gel and $1 \mathrm{~g}$ anhydrous sodium sulfate. The elution was subsequently carried out using $20 \mathrm{ml}$ of hexane/dichloromethane $(7: 3, v / v)$. The effluent was concentrated to a final volume of $1 \mathrm{ml}$ for GC analysis. Reagent blanks were also analyzed simultaneously with the experimental samples. In addition, several grams of soil were dried for $8 \mathrm{~h}$ at $80^{\circ} \mathrm{C}$ to calculate moisture content.

\section{Chromatographic analysis}

An Agilent 6890 gas chromatograph (GC) equipped a ${ }^{63} \mathrm{Ni}$ electron capture detector $(\mu \mathrm{ECD})$ (Agilent Technologies, Wilmington, DE, USA) was used for the analysis. The column used was HP-5 silica capillary column with $30 \mathrm{~m} \times 0.32 \mathrm{~mm}$ i.d. $\times 0.25 \mu \mathrm{m}$ film thickness. The purified extract was analyzed by GC- $\mu$ ECD under splitless injection mode with ultrapure nitrogen as the carrier gas and the make-up gas. The injector and detector temperatures were 220 and $300^{\circ} \mathrm{C}$, respectively. The oven temperature was initially set at $100^{\circ} \mathrm{C}$ with a $2-\mathrm{min}$ hold, ramped at $10^{\circ} \mathrm{C} / \mathrm{min}$ to $160^{\circ} \mathrm{C}$ with a $2-\mathrm{min}$ hold, $4^{\circ} \mathrm{C} / \mathrm{min}$ to $230^{\circ} \mathrm{C}$ with a 5 -min hold, $10^{\circ} \mathrm{C} / \mathrm{min}$ to $270^{\circ} \mathrm{C}$ with a 2 -min hold. $\mathrm{HCH}$ and DDT were identified by retention time matched to standards and were quantified based on peak area. The measured $\mathrm{HCH}$ and DDT include four $\mathrm{HCH}$ isomers and four DDT homologues. The concentrations of $\sum \mathrm{HCH}$ and $\sum$ DDT are the sum of the four $\mathrm{HCH}$ isomers and 
four DDT homologues, respectively. The $\mathrm{HCH}$ and DDT concentrations in soil are reported on a dry weight basis.

\section{Quality control}

For quality assurance and control, procedural blanks and matrixes spiked with the standard solution were analyzed. None of the target compounds were detected in the procedural blanks. All solvents used were distilled in glass (PR grade) and were checked for interferences or contamination prior to use. The recovery rate of $\mathrm{HCH}$ and DDT spiked to soil ranged from 73.3 to $96.2 \%$. Extraction efficiency, as indicated by recovery of the surrogate standards (TCMX), was $75 \pm 10 \%$. The limits of detection (LOD) were described as three times the signal-to-noise ratio (S/ $\mathrm{N})$. The detection limit ranged from 0.05 to $0.20 \mathrm{ng} \mathrm{g}^{-1}$. GC analysis was repeated twice for each replicate sample and the relative standard deviation (RSD) of replicate analyses was less than $10 \%$.

Soil physicochemical characteristics analysis

Soil $\mathrm{pH}$ was measured ( $10 \mathrm{~g}$ of air-dried soil suspended in $25 \mathrm{ml}$ deionized water) using a $\mathrm{pH}$ meter. Total organic carbon (TOC) and total nitrogen (TN) were analyzed by Universal CHNOS Elemental Analyzer (Elementar Vario EL III, Germany).

Statistical analysis

The software used for mapping the sampling sites was ArcGis (ESRI, US). SPSS 11.5 for Windows was employed for statistical analysis. Correlation analysis was used to explore the relationship between $\mathrm{HCH}$ and DDT and selected soil properties.

\section{Results and discussion}

Concentrations of $\mathrm{HCH}$ and DDT in the study area

The range, mean, and median concentrations of $\mathrm{HCH}$ and DDT around the watersheds of Beijing water reservoirs are shown in Table 1. The mean concentrations of $\sum \mathrm{HCH}$ and $\sum \mathrm{DDT}$ were 0.67 and $6.64 \mathrm{ng} \mathrm{g}^{-1}$, ranging from $<\mathrm{LOD}$ to $5.56 \mathrm{ng} \mathrm{g}^{-1}$ and $<\mathrm{LOD}$ to $117 \mathrm{ng} \mathrm{g}^{-1}$, respectively. $\mathrm{HCH}$ and DDT were not detected in many locations, or were present only in amounts that were below the detection limit. The high standard deviations of $\mathrm{HCH}$ and DDT concentrations indicated high variability of $\mathrm{HCH}$ and DDT distribution. In comparison to $\mathrm{HCH}$ concentrations in soils from other areas, the mean concentration in the study area was lower than the residual levels reported for the Tibetan plateau (range: 0.18-5.38, mean: 1.97; Fu et al. 2001), the Pearl River delta (range: 0.05-24.1, median: 2.94; Li et al. 2006), central Germany (range: 4.60-11.5, mean: 7.52; Manz et al. 2001) and Romania (range: 2.8-89.5, mean: 26.1; Covaci et al. 2001). DDT levels in this area were higher than those in soils from the Taihu Lake region (range: 0.3-5.3; Feng et al. 2003) and the mountain Andean lakes (range:0.10-1.10; Borghini et al. 2005), but were significantly lower than those of the Pearl River delta (range: 0.52-414, median: 20.1; Li et al. 2006), central Germany (range: $23.7-173$, mean: 72.0; Manz et al. 2001) and Romania (range: 9-187.4, mean: 62.5; Covaci et al. 2001). Overall, the concentrations of $\mathrm{HCH}$ and DDT in soils around the Beijing watersheds were lower than those in other places.

The concentrations of $\mathrm{HCH}$ and DDT in our soils were compared with the soil-quality reference values recommended in China and in the Netherlands (Table 1). According to the Guidelines of Chinese Environmental Quality Standard for Soils (GB156181995), and the Dutch target values (NMH 2000), the concentrations of $\sum \mathrm{HCH}$ in all samples were lower than the first grade $\left(50 \mathrm{ng} \mathrm{g}^{-1}\right)$ of the Chinese environmental quality standard and Dutch target values $\left(10 \mathrm{ng} \mathrm{g}^{-1}\right)$. The mean concentrations of $\alpha$ $\mathrm{HCH}$ and $\beta$-HCH were also within the limit of Dutch target values. The mean concentrations of $\sum D D T$ in 101 samples were below the first grade $\left(50 \mathrm{ng} \mathrm{g}^{-1}\right)$, those in three samples were above the first grade but beneath the second grade (500 $\mathrm{ng} \mathrm{g}^{-1}$ ), and there were 16 soil samples exceeded the Dutch target values (10 $\mathrm{ng} \mathrm{g}^{-1}$ ) but were much lower than the intervention values $\left(4,000 \mathrm{ng} \mathrm{g}^{-1}\right)$. According to the Guideline of Chinese Environmental Quality Standard, the maximum permitted concentration of both $\mathrm{HCH}$ and DDT in the soil should be less than $500 \mathrm{ng} \mathrm{g}^{-1}$ in order to ensure the safety of agricultural products and to prevent food contamination from pesticides, which can damage human health. The data of this study showed that the levels of $\mathrm{HCH}$ and DDT in soils 
Table 1 Concentrations (ng $\mathrm{g}^{-1} \mathrm{dw}$ ) of $\mathrm{HCH}$ and DDT in soils around the Beijing watershed

\begin{tabular}{|c|c|c|c|c|c|c|c|c|}
\hline \multirow[t]{2}{*}{ OCPs } & \multirow[t]{2}{*}{ Mean } & \multirow[t]{2}{*}{ SD } & \multirow[t]{2}{*}{ Minimum } & \multirow[t]{2}{*}{ Maximum } & \multirow[t]{2}{*}{ Median } & \multirow[t]{2}{*}{ Detection rate $(\%)$} & \multicolumn{2}{|c|}{ Target values } \\
\hline & & & & & & & $\mathrm{Chn}^{\mathrm{d}}$ & Neth $^{\mathrm{e}}$ \\
\hline$\alpha-\mathrm{HCH}$ & 0.01 & 0.04 & $<\mathrm{LOD}$ & 0.27 & 0.00 & 10.77 & & 3 \\
\hline$\beta-\mathrm{HCH}$ & 0.46 & 0.75 & $<\mathrm{LOD}$ & 4.58 & 0.28 & 59.31 & & 9 \\
\hline$\gamma-\mathrm{HCH}$ & 0.14 & 0.17 & $<\mathrm{LOD}$ & 1.01 & 0.12 & 62.19 & & 0.05 \\
\hline$\delta-\mathrm{HCH}$ & 0.05 & 0.21 & $<\mathrm{LOD}$ & 1.53 & 0.00 & 11.23 & & \\
\hline$\sum \mathrm{HCH}^{\mathrm{a}}$ & 0.67 & 0.95 & $<\mathrm{LOD}$ & 5.56 & 0.40 & 83.73 & 50 & 10 \\
\hline$p, p^{\prime}$-DDE & 3.11 & 8.61 & $<\mathrm{LOD}$ & 78.07 & 0.78 & 81.69 & & \\
\hline$p, p^{\prime}$-DDD & 0.16 & 0.65 & $<\mathrm{LOD}$ & 5.71 & 0.00 & 17.46 & & \\
\hline$o, p^{\prime}$-DDT & 0.59 & 1.58 & $<\mathrm{LOD}$ & 9.04 & 0.00 & 34.54 & & \\
\hline$p, p^{\prime}$-DDT & 2.72 & 6.65 & $<\mathrm{LOD}$ & 50.73 & 0.97 & 91.19 & & \\
\hline$\sum \mathrm{DDT}^{\mathrm{b}}$ & 6.64 & 15.3 & $<\mathrm{LOD}$ & 116.74 & 1.91 & 93.31 & 50 & 10 \\
\hline Ratio $^{\mathrm{c}}$ & 0.04 & 0.13 & 0.00 & 0.73 & 0.00 & & & \\
\hline Ratio $2^{\mathrm{c}}$ & 1.00 & 1.10 & 0.00 & 5.49 & 0.64 & & & \\
\hline
\end{tabular}

Mean, SD, minimum, maximum and median were calculated assuming less than LOD (limits of detection) were equal to zero for statistical purpose

${ }^{\text {a }} \sum \mathrm{HCH}=\alpha-\mathrm{HCH}+\beta-\mathrm{HCH}+\gamma-\mathrm{HCH}+\delta-\mathrm{HCH}$

b $\sum \mathrm{DDT}=p, p^{\prime}-\mathrm{DDE}+p, p^{\prime}-\mathrm{DDD}+o, p^{\prime}$-DDT $+p, p^{\prime}$-DDT

${ }^{c}$ Ratio1 $=\alpha-\mathrm{HCH} / \gamma-\mathrm{HCH} ; \mathrm{Ratio} 2=\left(p, p^{\prime}\right.$-DDE $+p, p^{\prime}$-DDD $) / p, p^{\prime}$-DDT

${ }^{\mathrm{d}}$ Chn: Chinese environmental quality standard for soils (GB15618-1995)

e Neth: The Netherlands target values for soil remediation (2000)

around GTR were significantly lower than the mandatory safe values. Although almost all of the $\mathrm{HCH}$ and DDT concentrations in soils were much lower than the Chinese Environmental Quality Standard, the $\mathrm{HCH}$ and DDT concentrations, especially DDT, in some sites were higher than the Dutch target values for soil remediation. As a result, further soil remediation may be essential for improving soil quality to reach the international standard for producing and exporting agricultural products in this region.

The mean percentages of $\mathrm{HCH}$ isomers in soils were as follows: $\beta-\mathrm{HCH}>\gamma-\mathrm{HCH}>\delta-\mathrm{HCH}>\alpha-\mathrm{HCH}$. A relatively high proportion of $\beta-\mathrm{HCH}(69 \%$ of $\left.\sum \mathrm{HCH}\right)$ confirmed that the technical $\mathrm{HCH}$ had not been used in this region recently (Zhu et al. 2005). The predominance of $\beta-\mathrm{HCH}$ among $\mathrm{HCH}$ in most soil samples suggested that $\mathrm{HCH}$ was mainly from historical inputs (Toan et al. 2007). The mean ratio of $\alpha-\mathrm{HCH} / \gamma-\mathrm{HCH}$ was 0.04 with a maximum of 0.73 , and the ratios were zero in $90 \%$ of the samples, which were much lower than the $\alpha / \gamma-\mathrm{HCH}$ ratio found in the technical $\mathrm{HCH}$ mixture, possibly indicating an input of lindane in the past several years or that more $\alpha$ $\mathrm{HCH}$ has evaporated into atmosphere from soil with time (Gao et al. 2008). The mean composition of DDT compounds in soils was as follows: $p, p^{\prime}-$ $\mathrm{DDE}>p, p^{\prime}$-DDT $>o, p^{\prime}$-DDT $>p, p^{\prime}$-DDD, with the $p, p$ '-DDE accounted for a major composition of DDT ( $48 \%$ of $\left.\sum D D T\right)$. This indicated that the DDT contamination of the soil occurred in the past and that a substantial amount of aerobic degradation of DDT has already taken place. During the dry season, because of the aerobic soil conditions, the active oxidative transformation of $p, p$ '-DDT to $p, p$ '-DDE was expected (Toan et al. 2007). The higher concentration of DDE found in this area was most likely related to the longer persistence of DDE than that of DDD and their parent compound, DDT. The predominance of metabolites with respect to parent compounds suggested a contamination mainly by runoff from aged and weathered agricultural soils (Miglioranza et al. 2004). The ratio of ( $p, p^{\prime}$ $\mathrm{DDE}+p, p^{\prime}$-DDD) $/ p, p^{\prime}$-DDT was $<1$ in $63 \%$ of the soil samples, and the high proportion of $p, p^{\prime}$ DDT (41\% of $\sum$ DDT) indicated a recent input of DDT had occurred at some sampling sites. This could be explained by that after the ban on the use of $\mathrm{HCH}$ and DDT in agricultural production was enforced, the 
input of agricultural application had been cut, while the input from weathered agricultural soils and atmospheric deposition may have served as continuous sources of the residue (Villa et al. 2003; Gioia et al. 2005).

Effect of land use on the $\mathrm{HCH}$ and DDT residues

Land use is a pivotal factor that affects $\mathrm{HCH}$ and DDT residues because different land uses can lead to the differences in the quantity of $\mathrm{HCH}$ and DDT applied, $\mathrm{HCH}$ and DDT remediation capacities, cultivation pattern, and soil physico-chemical and biological properties (Harner et al. 1999; Gong et al. 2004; Wang et al. 2005a; Gaw et al. 2006). Soils collected from different land-use patterns were analyzed to determine the effects of land use on $\mathrm{HCH}$ and DDT residues. Soil samples in the study area were categorized into three types of land uses as orchards, farmlands, and fallow lands. The average concentrations of $\mathrm{HCH}$ and DDT in soils under three land uses are presented in Table 2. The total concentration of $\mathrm{HCH}$ in soils varied only slightly among land use categories, which may be due to the relatively higher vapor pressure of $\mathrm{HCH}$ making it much easier to volatilize than DDT from soil to atmosphere (Zhang et al. 2006). The levels of DDT in soils under the three land-use types differed from those of $\mathrm{HCH}$. The mean levels of $\sum$ DDT decreased in the following order: orchard $>$ farmland $>$ fallow. The total concentrations of DDT in arable soils were significantly $(p<0.05)$ higher than those in fallow soils, suggesting that DDT was mostly used for agricultural activities in this region over the past years. In addition, the highest levels of $\mathrm{HCH}$ and DDT were all found in orchard soil, which confirmed that fruit and vegetable cultivation used high levels of $\mathrm{HCH}$ and DDT. The lower pesticide concentrations detected in fallow soils might be due to drift of pesticides and volatilization from the nearby agricultural areas (Miglioranza et al. 2003b), followed by atmospheric deposition (Harner et al. 1999). From the atmosphere, pesticides can be delivered to the terrestrial environment via dry or wet deposition (Shegunova et al. 2007).

The relative concentrations of the parent compounds and their metabolites/isomers can provide useful information on the origin of these compounds, the history of how they were imputed into the environment, and possible degradation pathways involved (Wang et al. 2007b). Among all HCH isomers, $\beta-\mathrm{HCH}$ is the most stable and persistent to microbial degradation. The ratio of $\beta-\mathrm{HCH} / \gamma-\mathrm{HCH}$ can increase during the degradation process. We used the ratio of $\beta-\mathrm{HCH} / \gamma-\mathrm{HCH}$ to reflect the degradation of $\mathrm{HCH}$ in soils (Fig. 2). There was no significant difference in the ratios of $\beta-\mathrm{HCH} / \gamma-\mathrm{HCH}$ in soils under the three land-use types, which indicated that land use might not have a significant influence on the degradation of $\mathrm{HCH}$ in soils, or the ratio of $\beta-\mathrm{HCH} / \gamma$ $\mathrm{HCH}$ does not represent the influence of land uses on HCH degradation in soils (Wang et al. 2007a). Since DDT levels in the natural environment will decrease with time and the major metabolites are expected to be DDE and DDD, the ratio of metabolite/parent compound can be used to understand the degradation pathway of DDT in soils (Wang et al. 2007a). The ratios of (DDD + DDE)/DDT in soils under three land uses were: Orchard $\approx$ Farmland $>$ fallow (Fig. 2). The small ratio of (DDD + DDE)/DDT in the fallow soils suggested that degradation of DDT was the slowest (Miglioranza et al. 2003a). This could also be explained by the fact that the fallow soils were not subject to mechanical mixing (e.g., plowing and disking) or fertilization, which would otherwise enhance microbial action (Harner et al. 1999). The accumulation patterns of HCH and DDT in different soils represented a dynamic balance between deposition and erosion in association with tillage management practices and the effects of natural processes such as rainfall and flooding (Miglioranza et al. 2003a).

\section{Effect of soil textures on the HCH and DDT} residues

The fact that $\mathrm{HCH}$ and DDT are still present in measurable concentrations in many of the sampled soils means that these residues resisted degradation, leaching, and volatilization due to strong sorption (Hilber et al. 2008). The intensity of HCH and DDT degradation depends upon several environmental factors and soil parameters such as total organic carbon (TOC), soil texture, soil $\mathrm{pH}$, water content and temperature, as well as the structure of the pesticides (Manz et al. 2001; Wenzel et al. 2002; Miglioranza et al. 2003a; Hilber et al. 2008). In this study, soil samples were categorized into four types of textures 
Table 2 Concentrations ( $\mathrm{ng} \mathrm{g}^{-1} \mathrm{dw}$ ) of $\mathrm{HCH}$ and DDT in soils under three land-use types

\begin{tabular}{|c|c|c|c|c|c|c|}
\hline \multirow[t]{2}{*}{ OCPs } & \multicolumn{2}{|c|}{ Orchard $(n=39)$} & \multicolumn{2}{|c|}{ Farmland $(n=51)$} & \multicolumn{2}{|c|}{ Fallow $(n=14)$} \\
\hline & Mean & SD & Mean & SD & Mean & SD \\
\hline$\alpha-\mathrm{HCH}$ & 0.01 & 0.02 & 0.01 & 0.04 & 0.03 & 0.06 \\
\hline$\beta-\mathrm{HCH}$ & 0.57 & 1.01 & 0.37 & 0.40 & 0.45 & 0.93 \\
\hline$\gamma-\mathrm{HCH}$ & 0.15 & 0.16 & 0.16 & 0.17 & 0.07 & 0.13 \\
\hline$\delta$-HCH & 0.03 & 0.08 & 0.05 & 0.21 & 0.14 & 0.41 \\
\hline$\sum \mathrm{HCH}$ & 0.76 & 1.13 & 0.59 & 0.57 & 0.70 & 1.46 \\
\hline$p, p^{\prime}-\mathrm{DDE}$ & 4.67 & 12.80 & 2.47 & 4.91 & 1.11 & 1.83 \\
\hline$p, p^{\prime}$-DDD & 0.12 & 0.31 & 0.21 & 0.86 & 0.13 & 0.47 \\
\hline$o, p^{\prime}$-DDT & 0.82 & 1.93 & 0.37 & 1.12 & 0.71 & 1.93 \\
\hline$p, p^{\prime}$-DDT & 3.50 & 8.98 & 2.43 & 5.29 & 1.62 & 1.90 \\
\hline$\sum \mathrm{DDT}$ & 9.10 & 21.02 & 5.61 & 11.41 & 3.56 & 5.27 \\
\hline
\end{tabular}

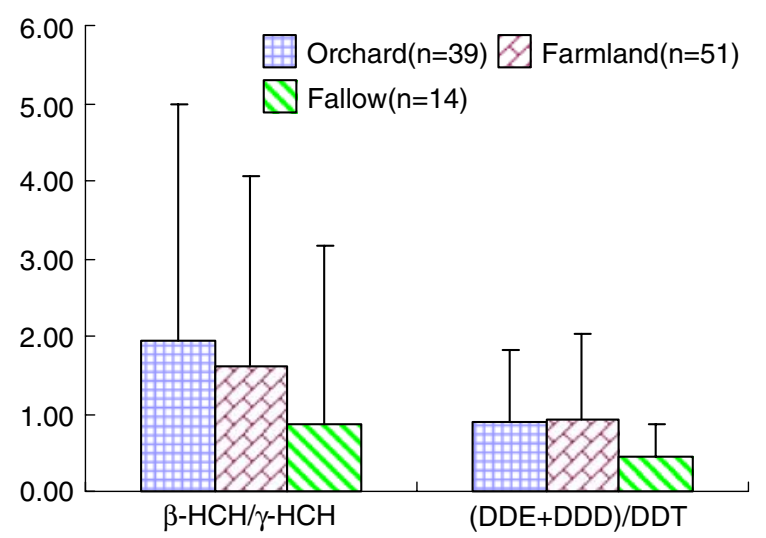

Fig. 2 Ratios of $\beta-\mathrm{HCH} / \gamma-\mathrm{HCH}$ and (DDD + DDE)/DDT in soils under different land-use types

(loam, light loam, sandy loam, and sandy soil) to delineate the influence of soil texture on $\mathrm{HCH}$ and DDT residue levels. The concentrations of $\mathrm{HCH}$ and DDT by different soil textures are given in Fig. 3.

For $\mathrm{HCH}$ and its isomers, the highest levels were found in sandy loam soil, which may be explained because the sandy loam soil together with intensive cropping in this soil (Sparovek et al. 2001). No significant difference was found in $\mathrm{HCH}$ residues among the other soil textures. This mainly results from $\mathrm{HCH}$ 's higher water solubility, vapor pressure, and high Henry's law constant than that of DDT. In this regard, $\mathrm{HCH}$ has a stronger ability to degrade and transfer from soil into liquid and atmosphere (Shi et al. 2005). For DDT and its metabolites, the residues in loamy soil were significantly higher than those in sandy soil, which were similar to the soils from GTR in the previous study (Wang et al. 2005a). This could be explained because, compared to sandy soil, loamy soil can hold more moisture and organic materials, which have the effect of strengthening the ability of the soil particles to adsorb DDT, as well as the ability of decelerating the degradation and cleanup process of this pollutant. In general, it is assumed that the influence of soil texture on the absorption of $\mathrm{HCH}$ and DDT is minor compared to the influence from land uses.
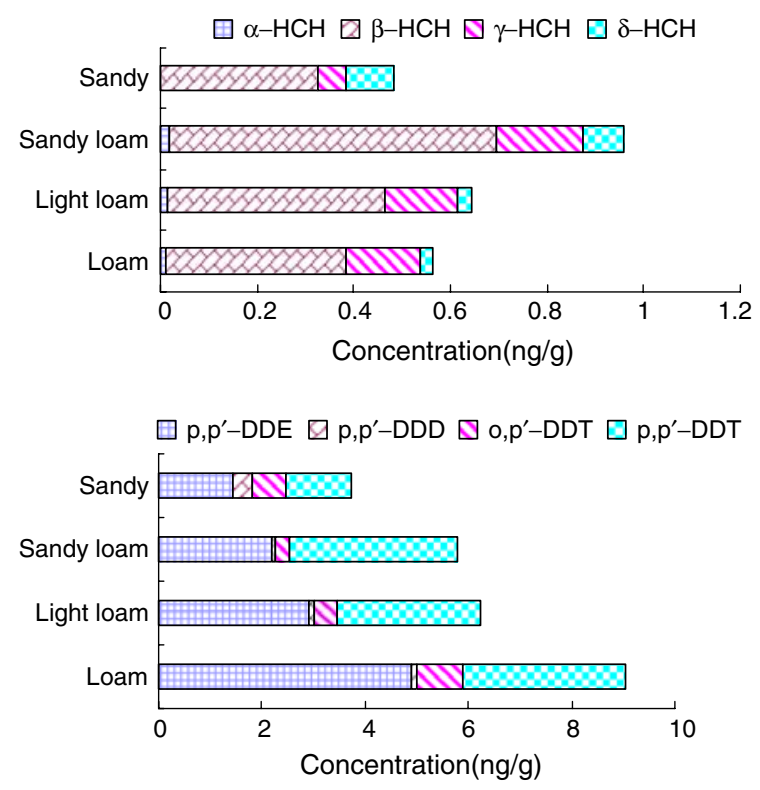

Fig. 3 Concentrations ( $\mathrm{ng} \mathrm{g}^{-1} \mathrm{dw}$ ) of $\mathrm{HCH}$ and DDT in soils with different textures 
Table 3 Correlations between HCH and DDT and selected soil properties

\begin{tabular}{llllclllrrr}
\hline & $\alpha-\mathrm{HCH}$ & $\beta$-HCH & $\gamma$-HCH & $\delta$-HCH & $\sum \mathrm{HCH}$ & $p, p^{\prime}$-DDE & $p, p^{\prime}$-DDD & $o, p^{\prime}$-DDT & $p, p^{\prime}$-DDT & $\sum$ DDT \\
\hline TOC & $0.35^{* *}$ & $0.27^{* *}$ & $0.25^{* *}$ & 0.03 & $0.28^{* *}$ & 0.19 & -0.02 & 0.08 & 0.14 & 0.19 \\
TN & 0.02 & 0.05 & 0.07 & -0.11 & 0.03 & 0.07 & -0.09 & -0.05 & 0.03 & 0.05 \\
$\mathrm{pH}$ & 0.06 & 0.04 & -0.01 & $0.20^{* *}$ & 0.08 & 0.02 & 0.07 & 0.01 & -0.12 & -0.04 \\
\hline
\end{tabular}

** Correlation is significant at the 0.01 level

Effect of soil physicochemical properties on $\mathrm{HCH}$ and DDT residues

Soil physicochemical properties play a role in determining the concentrations of pollutants. These parameters affect both the current concentration in the soil system as well as possible adsorption onto various soil components (Zhang et al. 2005). The increase of organic carbon content in soil can increase the amount of microbial biomass and thus can induce the degradation or absorption (Wang et al. 2007a). As a result, total organic carbon (TOC) content could affect the residue levels of $\mathrm{HCH}$ and DDT in soils (Zhang et al. 2006). Soil pH can affect the concentrations of $\mathrm{HCH}$ and DDT in soil by influencing the microbiological activity in the soil (Wenzel et al. 2002). There have been few reports about the relationship between $\mathrm{HCH}$ and DDT residues and total nitrogen (TN) content in soil. In this study, the physicochemical properties of soil (TOC, TN, and $\mathrm{pH}$ ) were analyzed to examine the possible relationship with $\mathrm{HCH}$ and DDT residues.

The results of correlation analyses among $\mathrm{HCH}$, DDT, TOC, and $\mathrm{pH}$ are listed in Table 3. Significant positive correlations among a-HCH, $\beta$ - $\mathrm{HCH}, \gamma-\mathrm{HCH}$, $\sum \mathrm{HCH}$ and $\beta-\mathrm{HCH} / \gamma-\mathrm{HCH}$ with TOC, and between $\delta$ - $\mathrm{HCH}$ and $\mathrm{pH}$ were observed. The correlation between $\mathrm{HCH}$ and TOC suggests binding of $\mathrm{HCH}$ to soil organic matter (Zhu et al. 2005). A correlation between $\mathrm{pH}$ and $\delta$-HCH was found, but such relationships were not found for DDT and other $\mathrm{HCH}$ isomers, indicating that soil $\mathrm{pH}$ has no obvious effect on DDT and $\mathrm{HCH}$ residues in the study area. There were no significant correlations between DDT concentrations and TOC content, $\mathrm{HCH}$ and DDT concentrations and $\mathrm{TN}$, which indicated that the residue levels were a reflection of DDT application history and dissipation rates rather than air-soil equilibrium, which is similar to the agricultural soils from Alabama, USA (Harner et al. 1999) and Georgia, USA (Kannan et al. 2003) and different from the surface soils from Tianjin, China (Gong et al. 2004). These results show that the degradation of HCH and DDT is complex and is affected by many factors. It is therefore impossible to use a single soilgeochemical factor to predict the distribution of $\mathrm{HCH}$ and DDT residues in soils at the regional scale (Hao et al. 2008).

\section{Conclusions}

The results of this study elucidated the distribution and factors affecting $\mathrm{HCH}$ and DDT in soils from orchards, farmlands, and fallow land around the Beijing watershed. Compared to the earlier studies of $\mathrm{HCH}$ and DDT in soils and established reference values, the pollution due to $\mathrm{HCH}$ and DDT was generally low in soils around our study area. Land uses and soil characteristics account for the considerable differences in $\mathrm{HCH}$ and DDT accumulation among the studied soils. HCH and DDT concentrations were higher in arable soils than those in uncultivated fallow soils. $\mathrm{HCH}$ residues were highest in sandy loam soil, compared to DDT residues, which were highest in loamy soil. A significant positive correlation $(p<0.01)$ between TOC and HCH indicated that TOC could enhance absorption of $\mathrm{HCH}$ in soils. The results indicated that $\mathrm{HCH}$ and DDT residues in soils were mainly from the historical application. Atmospheric deposition, as well as longdistance transportation and surrounding weathered agricultural soils, may also serve as sources of $\mathrm{HCH}$ and DDT residues. Further soil remediation will be essential for improving soil quality of arable land to safeguard the quality of food. 
Acknowledgments This study was supported by the National Basic Research Program of China ("973" Research Program) with Grant No. 2007CB407307, the Knowledge Innovation Program of the Chinese Academy of Sciences with Grant No. KZCX2-YW-420-5, the National Key Technology R\&D Program with Grant No. 2008BAC32B07, and the National Natural Science Foundation of China with Grant No. 40601089. The authors are grateful to Professor Kurunthachalam Kannan, Wadsworth Center, Albany, New York, for his constructive comments.

\section{References}

Bergstrom, L., \& Stenstrom, J. (1998). Environmental fate of chemicals in soil. Ambio, 27, 16-23.

Borghini, F., Grimalt, J. O., Sanchez-Hernandez, J. C., Barra, R., Garcia, C. J. T., \& Focardi, S. (2005). Organochlorine compounds in soils and sediments of the mountain Andean lakes. Environmental Pollution, 136, 253-266. doi:10.1016/j.envpol.2005.01.007.

Covaci, A., Hura, C., \& Schepens, P. (2001). Selected persistent organochlorine pollutants in Romania. The Science of the Total Environment, 280, 143-152. doi:10.1016/S00489697(01)00820-8.

Feng, K., Yu, B. Y., Ge, D. M., Wong, M. H., Wang, X. C., \& Cao, Z. H. (2003). Organo-chlorine pesticide (DDT and $\mathrm{HCH})$ residues in the Taihu lake region and its movement in soil-water system I. Field survey of DDT and $\mathrm{HCH}$ residues in ecosystem of the region. Chemosphere, 50, 683-687. doi:10.1016/S0045-6535(02)00204-7.

Fu, S., Chu, S. G., \& Xu, X. B. (2001). Organochlorine pesticide residue in soils from Tibet, China. Bulletin of Environmental Contamination and Toxicology, 66, 171177. doi:10.1007/s001280000221.

Gao, F., Jia, J. Y., \& Wang, X. M. (2008). Occurrence and ordination of dichlorodiphenyltrichloroethane and hexachlorocyclohexane in agricultural soils from Guangzhou, China. Archives of Environmental Contamination and Toxicology, 54, 155-166. doi:10.1007/s00244-007-9023-3.

Gaw, S. K., Wilkins, A. L., Kim, N. D., Palmer, G. T., \& Robinson, P. (2006). Trace element and Sigma DDT concentrations in horticultural soils from the Tasman, Waikato and Auckland regions of New Zealand. The Science of the Total Environment, 355, 31-47. doi:10.1016/j.scitotenv. 2005.02.020.

Gioia, R., Offenberg, J. H., Gigliotti, C. L., Totten, L. A., Du, S., \& Eisenreich, S. J. (2005). Atmospheric concentrations and deposition of organochlorine pesticides in the US Mid-Atlantic region. Atmospheric Environment, 39, 2309-2322. doi:10.1016/j.atmosenv.2004.12.028.

Gong, Z. M., Tao, S., Xu, F. L., Dawson, R., Liu, W. X., Cui, Y. H., et al. (2004). Level and distribution of DDT in surface soils from Tianjin, China. Chemosphere, 54, 1247-1253. doi:10.1016/j.chemosphere.2003.10.021.

Gonzalez-Lopez, N., Rial-Otero, R., Cancho-Grande, B., Simal-Gandara, J., \& Soto-Gonzalez, B. (2005). Occurrence of organochlorine pesticides in stream sediments from an industrial area. Archives of Environmental
Contamination and Toxicology, 48, 296-302. doi:10. 1007/s00244-004-0070-8.

Hao, H. T., Sun, B., \& Zhao, Z. H. (2008). Effect of land use change from paddy to vegetable field on the residues of organochlorine pesticides in soils. Environmental Pollution, 156, 1046-1052. doi:10.1016/j.envpol.2008.04.021.

Harner, T., Wideman, J. L., Jantunen, L. M. M., Bidleman, T. F., \& Parkhurst, M. J. (1999). Residues of organochlorine pesticides in Alabama soils. Environmental Pollution, 106, 323-332. doi:10.1016/S0269-7491(99)00110-4.

Hilber, I., Mader, P., Schulin, R., \& Wyss, G. S. (2008). Survey of organochlorine pesticides in horticultural soils and there grown Cucurbitaceae. Chemosphere, 73, 954-961. doi:10.1016/j.chemosphere.2008.06.053.

Kannan, K., Battula, S., Loganathan, B. G., Hong, C. S., Lam, W. H., Villeneuve, D. L., et al. (2003). Trace organic contaminants, including toxaphene and trifluralin, in cotton field soils from Georgia and South Carolina, USA. Archives of Environmental Contamination and Toxicology, 45, 30-36. doi:10.1007/s00244-002-0267-7.

Kannan, K., Kajiwara, N., Le Boeuf, B. J., \& Tanabe, S. (2004). Organochlorine pesticides and polychlorinated biphenyls in California sea lions. Environmental Pollution, 131, 425-434. doi:10.1016/j.envpol.2004.03.004.

Li, J., Zhang, G., Qi, S. H., Li, X. D., \& Peng, X. Z. (2006). Concentrations, enantiomeric compositions, and sources of $\mathrm{HCH}, \mathrm{DDT}$ and chlordane in soils from the Pearl River delta, South China. The Science of the Total Environment, 372, 215-224. doi:10.1016/j.scitotenv.2006.09.023.

Loganathan, B. G., \& Kannan, K. (1994). Global organochlorine contamination trends - an overview. Ambio, 23, 187-191.

Luo, W., Lu, Y. L., Giesy, J. P., Wang, T. Y., Shi, Y. J., Wang, G., et al. (2007). Effects of land use on concentrations of metals in surface soils and ecological risk around Guanting Reservoir, China. Environmental Geochemistry and Health, 29, 459-471. doi:10.1007/s10653-007-9115-z.

Manz, M., Wenzel, K. D., Dietze, U., \& Schuurmann, G. (2001). Persistent organic pollutants in agricultural soils of central Germany. The Science of the Total Environment, 277, 187198. doi:10.1016/S0048-9697(00)00877-9.

Miglioranza, K. S. B., De Moreno, J. E. A., \& Moreno, V. J. (2003a). Dynamics of organochlorine pesticides in soils from a southeastern region of Argentina. Environmental Toxicology and Chemistry, 22, 712-717. doi:10.1897/ 1551-5028(2003)022<0712:DOOPIS > 2.0.CO;2.

Miglioranza, K. S. B., de Moreno, J. E. A., \& Moreno, V. J. (2003b). Trends in soil science: Organochlorine pesticides in Argentinean soils. Journal of Soils and Sediments, 4(3), 264-265. doi:10.1007/BF02988686.

Miglioranza, K. S. B., de Moreno, J. E. A., \& Moreno, V. J. (2004). Land-based sources of marine pollution: Organochlorine pesticides in stream systems. Environmental Science and Pollution Research, 11, 227-232. doi:10.1007/BF02979630.

NMH.(2000). The Netherlands Ministry of Housing, Spatial Planning and Environment's Circular on target values and intervention values for soil remediation. http:// www2.minvrom.n1/Docs/internationaal/annexS_I2000.pdf.

Oliver, D. P., Kookana, R. S., \& Salama, R. B. (2003). Land use effects on sorption of pesticides and their metabolites 
in sandy soils. I. Fenamiphos and two metabolites, fenamiphos sulfoxide and fenamiphos sulfone, and fenarimol and azinphos methyl. Australian Journal of Soil Research, 41, 847-860. doi:10.1071/SR02094.

Shegunova, P., Klanova, J., \& Holoubek, I. (2007). Residues of organochlorinated pesticides in soils from the Czech Republic. Environmental Pollution, 146, 257-261. doi:10.1016/j.envpol.2006.03.057.

Shi, Y., Meng, F., Guo, F., Lu, Y., Wang, T., \& Zhang, H. (2005). Residues of organic chlorinated pesticides in agricultural soils of Beijing, China. Archives of Environmental Contamination and Toxicology, 49, 37-44. doi:10.1007/s00244-004-0087-z.

Sparovek, G., Anisimova, M. A., Kolb, M., Bahadir, M., Wehage, H., \& Schnug, E. (2001). Organochlorine compounds in a Brazilian watershed with sugarcane and intense sediment redistribution. Journal of Environmental Quality, 30, 2006-2010.

Toan, V. D., Thao, V. D., Walder, J., Schmutz, H. R., \& Ha, C. T. (2007). Contamination by selected organochlorine pesticides (OCPs) in surface soils in Hanoi, Vietnam. Bulletin of Environmental Contamination and Toxicology, 78, 195-200. doi:10.1007/s00128-007-9149-z.

Villa, S., Vighi, M., Maggi, V., Finizio, A., \& Bolzacchini, E. (2003). Historical trends of organochlorine pesticides in an Alpine glacier. Journal of Atmospheric Chemistry, 46, 295-311. doi:10.1023/A:1026316217354.

Wang, H. Z., He, M. C., Lin, C., Quan, X. C., Guo, W., \& Yang, Z. F. (2007a). Monitoring and assessment of persistent organochlorine residues in sediments from the Daliaohe River watershed, Northeast of China. Environmental Monitoring and Assessment, 133, 231-242. doi:10. 1007/s10661-006-9576-z.

Wang, F., Jiang, X., Bian, Y. R., Yao, F. X., Gao, H. J., Yu, G. F., et al. (2007b). Organochlorine pesticides in soils under different land usage in the Taihu lake region, China. Journal of Environmental Sciences (China), 19, 584-590. doi:10.1016/S1001-0742(07)60097-7.

Wang, X. F., Li, X. H., Cheng, H. X., Xu, X. B., Zhuang, G. M., \& Zhao, C. D. (2008a). Organochlorine pesticides in particulate matter of Beijing, China. Journal of Hazardous Materials, 155, 350-357. doi:10.1016/j.jhazmat.2007.11.116.

Wang, T. Y., Lu, Y. L., Dawson, R. W., Shi, Y. J., Zhang, H., \& Xing, Y. (2005a). Effects of environmental factors on organochlorine pesticide residues in soils of the Guanting Reservoir area, China. Journal of Environmental Science and Health. Part. B, Pesticides, Food Contaminants, and Agricultural Wastes, 41, 309-321. doi:10.1080/ 03601230500357538.

Wang, T. Y., Lu, Y. L., Shi, Y. J., Giesy, J. P., \& Luo, W. $(2007 \mathrm{c})$. Organochlorine pesticides in soils around
Guanting Reservoir, China. Environmental Geochemistry and Health, 29, 491-501. doi:10.1007/s10653-007-9118-9.

Wang, T. Y., Lu, Y. L., Shi, Y. J., \& Zhang, H. (2005b). Spatial distribution of organochlorine pesticide residues in soils surrounding Guanting Reservoir, People's Republic of China. Bulletin of Environmental Contamination and Toxicology, 74, 623-630. doi:10.1007/s00128-005-0629-8.

Wang, G., Lu, Y., Wang, T., Zhang, X., Han, J., Luo, W., et al. (2008b). Factors influencing the spatial distribution of organochlorine pesticides in soils surrounding chemical industrial parks. Journal of Environmental Quality, 37, 18. doi:10.2134/jeq2007.0084.

Wenzel, K. D., Manz, M., Hubert, A., \& Schuurmann, G. (2002). Fate of POPs (DDX, HCHs, PCBs) in upper soil layers of pine forests. The Science of the Total Environment, 286, 143-154. doi:10.1016/S0048-9697(01)00972-X.

Whylie, P., Albaigés, J., Barra, R., Bouwman, H., Dyke, P., Wania, F., et al. (2003). Global assessment of persistent toxic substances (pp. 207). Geneve: UNEP/GEF.

Wong, M. H., Leung, A. O. W., Chan, J. K. Y., \& Choi, M. P. K. (2005). A review on the usage of POP pesticides in China, with emphasis on DDT loadings in human milk. Chemosphere, 60, 740-752. doi:10.1016/j.chemosphere. 2005.04.028.

Xue, N. D., \& Xu, X. B. (2006). Composition, distribution, and characterization of suspected endocrine-disrupting pesticides in Beijing Guanting Reservoir (GTR). Archives of Environmental Contamination and Toxicology, 50, 463473. doi:10.1007/s00244-005-1097-1.

Xue, N., Xu, X., \& Jin, Z. (2005). Screening 31 endocrinedisrupting pesticides in water and surface sediment samples from Beijing Guanting Reservoir. Chemosphere, 61, 1594-1606. doi:10.1016/j.chemosphere.2005.04.091.

Xue, N., Zhang, D., \& Xu, X. (2006). Organochlorinated pesticide multiresidues in surface sediments from Beijing Guanting Reservoir. Water Research, 40, 183-194. doi:10.1016/j.watres.2005.07.044.

Zhang, H., Lu, Y. L., Dawson, R. W., Shi, Y. J., \& Wang, T. Y. (2005). Classification and ordination of DDT and $\mathrm{HCH}$ in soil samples from the Guanting Reservoir, China. Chemosphere, 60, 762-769. doi:10.1016/j.chemosphere.2005. 04.023 .

Zhang, H. B., Luo, Y. M., Zhao, Q. G., Wong, M. H., \& Zhang, G. L. (2006). Residues of organochlorine pesticides in Hong Kong soils. Chemosphere, 63, 633-641. doi:10.1016/j.chemosphere.2005.08.006.

Zhu, Y. F., Liu, H., Xi, Z. Q., Cheng, H. X., \& Xu, X. B. (2005). Organochlorine pesticides (DDTs and HCHs) in soils from the outskirts of Beijing, China. Chemosphere, 60, 770-778. doi:10.1016/j.chemosphere.2005.04.018. 